\title{
ABORDAGENS BIOGRÁFICAS DE PESQUISA E DISPOSICIONALISMO SOCIOLÓGICO
}

\author{
BIOGRAPHIC APPROACHES TO RESEARCH \\ AND SOCIOLOGICAL DISPOSITIONALISM
}

\author{
Lília Junqueira*
}

\section{Resumo}

As abordagens metodológicas biográficas são utilizadas nas Ciências Sociais e servem de instrumento nas pesquisas sociológicas disposicionalistas (Halbwachs, Bourdieu, Passeron, Elias, Lahire), embora sejam caraterizadas por tipologia múltipla e problemas epistemológicos diversos. O texto de Bourdieu A Ilusão Biográfica constitui um divisor de águas no uso da biografia, na medida em que levanta suspeitas sobre o real caráter sociológico do método. A proposta deste artigo é problematizar o uso das abordagens biográficas na Sociologia Disposicionalista, apontando os avanços alcançados por Lahire neste item. O autor opera uma ressignificação positiva, utilizando a investigação de trajetórias de vida de maneira original, ao propor a superação da ideia da ilusão biográfica, entre outras inovações.

Palavras-chave: Biografia. Ilusão Biográfica. Sociologias Disposicionalistas. Metodologia.

\begin{abstract}
The biographic methodological approaches are used in the social sciences and serve as an instrument in the sociological dispositionalist researches (Halbwachs, Bourdieu, Passeron, Elias, Lahire), although they are characterized by multiple typology and various epistemological problems. Bourdieu's text "The Biographical Illusion" constitutes a watershed in the use of the biography, as it raises suspicions about the real sociological character of the method. The proposal of this article is to problematize the use of biographic approaches in Dispositionalist Sociology, pointing out the advances achieved by Lahire in this matter. The author operates a positive resignification, using the investigation of life trajectories in an original way, by proposing the overcoming of the idea of the biographical illusion, among other innovations.
\end{abstract}

Keywords: Biography. Biographical Illusion. Dispositionalist Sociologies. Methodology.

\section{Definição e histórico da abordagem biográfica}

A noção genérica de biografia (escrita da narrativa de uma vida) surgiu no quinto século antes de Cristo, através do termo bios. $\mathrm{Na}$ Grécia antiga, bios se referia à narrativa da vida do cidadão. Ainda não existia a ideia de intimidade conforme conhecemos hoje. O indivíduo era definido por seu foro exterior. As bios gregas tinham por função fazer o elogio das personalidades nacionais, fazendo oposição à identidade persa. Além disso, Sócrates, propositor da maiêutica, a arte de falar da própria vida, dava a esta prática uma função pedagógico-filosófica importante, visando a efetivação do princípio "conhece a ti mesmo e conhecerás o universo e os deuses."

*Professora e pesquisadora do Departamento de Ciências Sociais da UFPB. Autora dos livros Cultura e classes sociais na perspectiva disposicionalista (2010) e Balzac para Sociólogos (2017). E-mail: ljunqueira904@gmail.com 
(PINEAU; LE GRAND, 2007, p. 20). A noção de biografia nasceu, portanto, com a História, ligadas pela fundamentação de ambas na dimensão temporal.

Retomada no século XIX, a prática da escrita biográfica se manifestou por outras formas. A partir de então, diante da reformulação da ideia de individualidade dos sujeitos no período pós-Revolução Francesa, a Literatura se apropriou da biografia e surgiram escritores que publicavam narrativas de vida pessoais, como por exemplo, as Confissões de Jean Jacques Rousseau. No entanto, apenas os notáveis ainda eram objeto de biografias, assim como na antiguidade. Somente no século XX, biografias de pessoas comuns passaram a interessar o público, sendo expostas na mídia e escritas por terceiros: os biógrafos (LE JEUNE, 1971).

A partir do século XX, a prática biográfica apresentou forte expansão e seu uso tornouse significativamente diversificado, inclusive pelas Ciências Humanas e Sociais, chegando a exercer a função de métodos de pesquisa. Surgiram leques de classificações as mais diversas, que procuraram especificar pontos de vista, formas de abordagem, procedimentos metodológicos e condicionamentos empíricos variados envolvendo a pesquisa biográfica. Neste contexto pluridisciplinar envolvendo História, Psicologia, Sociologia, Antropologia, dentre tantas outras ciências, a noção de biografia pode se apresentar na forma de história oral, história de vida, pesquisa de itinerários, trajetórias de vida, carreiras, entrevistas biográficas, entrevistas narrativas, autobiografias, entre outras terminologias. Diante desta vastidão de acepções, Daniel Bertaux (2006) sugere o uso básico do termo "abordagem biográfica” e não biografia, para fazer a diferença entre a vida narrada ou escrita pelo sujeito e os dados escritos resultantes de uma entrevista biográfica. Tendo em vista que esta última tem, para o entrevistado, objetivo exterior a si mesmo, bem além daquele de expressar espontaneamente as memórias pessoais, é mais adequado, segundo o autor, o uso do termo abordagem biográfica. Posteriormente, foram se consolidando procedimentos específicos de pesquisa em variadas ciências, que possibilitaram o uso da palavra método e metodologia em áreas definidas de pesquisa.

Há inúmeros complicadores epistemológicos na abordagem biográfica. Do ponto de vista da Sociologia, a princípio, trata-se de um método interessante, porque disponibiliza a fala dos sujeitos. A narrativa de uma vida não é somente individual, já que todo indivíduo vive em sociedade. A biografia apresenta a sociedade, da forma como é "vivida" pelos sujeitos. Nesse aspecto, é essencial enfrentar os problemas de lógica que surgem devido a sua fundamentação na dimensão temporal. A situação da entrevista biográfica, por exemplo, apresenta temporalidade diferente do seu conteúdo, da trajetória que está sendo narrada. Como decriptar a temporalidade real a partir dos tópicos escolhidos pelo entrevistado, em dada situação relacional única de entrevista?

Quanto, de que modo e em que direção aquilo que foi "vivido" se transforma, no momento em que é narrado e escrito, seja pelo autor da auto ou heterobiografia, seja pelo transcritor de uma entrevista? Talvez seja possível dar uma resposta, mas chegar a ela exigiria uma metapesquisa epistemológica que inevitavelmente tiraria o sociólogo do seu foco. A ordem 
do discurso escrito obedece a regras bem definidas de objetividade e clareza necessárias ao trabalho de análise. Em certa medida, essa ordem pode solapar a ordem da memória que o sujeito se esforça para organizar ao narrar acontecimentos. Há uma ruptura lógica importante entre a narrativa oral e a narrativa escrita, no tocante à coleta de dados de memória, que precisa ser levada em conta pelo pesquisador. Segundo Butnaru e Keller (2013, p. 3), a transcrição cria o "ponto semântico de contato" entre ambas. A narrativa de vida realizada pelo sujeito é apenas uma primeira revisão do tempo vivido. O resultado da entrevista é uma coprodução de dados entre o entrevistado e o entrevistador. $\mathrm{O}$ entrevistado inicia o processo, fazendo uma primeira reelaboração do que viveu. O entrevistador fará uma segunda ao coletá-la, o transcritor fará uma terceira, o pesquisador ao analisar os dados fará uma quarta e depois uma quinta, que será aquela escrita numa publicação ou trabalho de apresentação final.

no que diz respeito à relação à escrita, o texto final é um texto empobrecido que deve servir aos objetivos da pesquisa; em seguida, isto atrai a atenção sobre a expressão, portanto, sobre a forma discursiva inicial que é necessário relativizar a fim de melhor objetivá-la (BERTAUX, 2006, p. 212, grifo do autor).

Além do problema da ruptura entre oralidade e escrita que redefine a temporalidade da narativa biográfica, existem também as rupturas entre objetividade e subjetividade, história e experiência vivida, história e passado, narrativa e autoria, entre outras (HOULE, 1997). Tendo em vista este alto nível de complexidade, torna-se indispensável ao sociólogo levar em conta o estatuto do observado, construindo a distância necessária no interior da relação íntima estabelecida na entrevista. Ao criar um espaço de reconstrução compartilhada de saberes, o pesquisador contrai a dívida da responsabilidade de empregar, desenvolvendo a sensibilidade na abordagem e registro. Tal sensibilidade deve combinar-se com o esforço disciplinado na elaboração de critérios de análise para chegar, em tese, a objetivar, da melhor forma possível, por meio de dados de pesquisa, a subjetividade do vivido transmitida pelo entrevistado por meio da narrativa biográfica.

Estes problemas foram muito discutidos pelos sociólogos que enfrentaram o desafio de utilizar a abordagem biográfica. No histórico dessa utilização, é conhecido o emprego, sobretudo da história de vida, pela Escola de Chicago. William Thomas e Florian Znaniecki ${ }^{1}$ publicaram a primeira obra de referência, "The Polish Peasent in Europe and America" (1918-1920). Clifford Shaw, Burgess, Oscar Lewis, são outros nomes conhecidos nesta tradição, todos com obras publicadas, fundamentadas em sólidas pesquisas utilizando a abordagem empírica do método biográfico.

1 O histórico da abordagem biográfica a seguir foi sintetizado a partir da elaboração de LE GRAND, Jean Louis em Étude d'une experience communautaire à orientation thérapeutique. Histoire de vie de groupe. Perspectives Sociologiques. Tese de doutorado pela Université Paris VIII, 1987. 
Nos anos 1950-1960, o uso da biografia foi expandido, tanto nos Estados Unidos como na Ingalterra. Por exemplo, nos Estados Unidos, Oscar Lewis publicou "The Children of Sanchez. Autobiography of a mexican family" (1961), e na Inglaterra, no contexto dos Estudos Culturais, Richard Hoggart escreveu "The Uses of Literacy, aspects of working class life" (1957), ambos utilizando a história de vida.

No final dos anos 1960, foi a vez da França aderir à abordagem biográfica. Algumas obras já consideradas clássicas poderiam ser citadas a título de exemplo, como "Tante Suzanne et l'histoire de vie et du devenir social d'une femme" (Maurizio Catani, pesquisa realizada entre 1971 e 1979, e publicada em 1982). Daniel Bertaux publica em 1976 "Histoires de vie ou récits de pratiques? Méthodologie de l'approche biographique en sociologie”. Esta obra suscitou o debate que originou o artigo de Bourdieu A Ilusão Biográfica. Em 1980 e 1990, a tradição dos Anais no âmbito da História veio reforçar o debate, levando à releitura da obra de Maurice Halbwachs e seus livros sobre a memória, como por exemplo "La mémoire collective" de 1950. Nos anos 1980, há uma expansão do uso da abordagem biográfica na Sociologia, com a emergência de nomes como Michael Pollak, Jean Peneff, Jean Michel Chapoulie, Vincent de Gaulejac, Didier Démazière e Claude Dubar. Nos anos 2000, se destaca a contribuição de Bernard Lahire, sobretudo com "Portraits Sociologiques, dispositions et variations individuelles" (Retratos Sociológicos, disposições e variações individuais) de 2004.

\section{A abordagem biográfica na tradição disposicionalista}

Para situar a abordagem biográfica em qualquer tradição teórica, é essencial examinar, antes, qual é o estatuto do sujeito proposto por ela. No caso das teorias disposicionalistas, o sujeito não é uma entidade essencializada, separada do meio no qual interage, nem desligada das condições desta interação. Herdeira da tradição estruturalista, estas teorias consideram que a sociedade é constituída de uma rede de relações sociais criada no decorrer de processos de socialização de longo prazo. A investigação da realidade deve, portanto, não procurar o indivíduo apenas observando como sua reunião em grupos constitui a sociedade, mas sim, ao contrário, estudar a emergência do indivíduo a partir da, e condicionada pela, rede de relações sociais na qual ele se socializa e interage.

O sujeito, indivíduo, ou ator social, também chamado por Bourdieu (1980) e Passeron (1990) de agente social (denominação decorrente justamente desta impossibilidade lógica de desligar indivíduo e sociedade), é construído no interior de condições sociais condicionantes que estavam definidas, em diferentes graus, antes que ele nascesse e continuam funcionando após a sua morte. A biografia do agente social, enquanto método de pesquisa, consiste, portanto, em buscar entender de que modo o agente expressa a sociedade em si mesmo à medida em que vive, e como sua trajetória de vida é condicionada por uma consciência coletiva exterior a ele. Por isso, para os disposicionalistas, o método biográfico se confunde com o estudo dos processos de 
socialização dos agentes, uma vez que é por estes processos fundantes que a sociedade conforma, até certo ponto, os indivíduos e, ao mesmo tempo, é conformada por eles.

Embora levem em alta conta a dimensão temporal da trajetória do agente, as primeiras pesquisas disposicionalistas fazem um corte na dimensão histórica para priorizar a análise do espaço temporal, mostrando o resultado prático do processo de socialização. Se Bourdieu (1980) desenvolve bastante esta posição analítica através do conceito de campo social, que é mais estático, outros autores como Elias (1994) e Bernard Lahire (2004) vão preferir priorizar o conceito de habitus, não sem questioná-lo, mas pelo fato de ser mais dinâmico e mais afeito às lógicas diacrônicas, dando maior relevância à dimensão temporal. Disso resulta que Bourdieu vê o indivíduo (agente) e sua socialização, ou sua biografia, muito mais conformados às determinações do espaço social, às regras impostas pelos campos sociais, do que Elias e Lahire. Estes consideram o processo de socialização não mais solto, ou mais independente da rede de relações, mas veem que esta rede é muito mais flexível do que parece na ótica dos campos, exatamente porque ela é continuamente atravessada pelos processos temporais, pela vida cotidiana dos indivíduos, que as modifica no decorrer do tempo. Por isso mesmo, estes autores dão maior importância à biografia enquanto instrumento de pesquisa capaz de gerar dados para a explicação da ação social.

Em Norbert Elias (1994), os indivíduos, ao interagirem, constróem teias de interdependência que produzem configurações de variados tipos, abrangendo desde estruturas menores e íntimas como a família, o grupo social próximo e o grupo de trabalho, até estruturas maiores, tais como a cidade, a comunidade, Estado e nação. A utilização da biografia será marcada, nesse autor, pela indissociabilidade entre indivíduo e sociedade nos termos do tradicional dilema sociológico entre agência e estrutura. Para ele as esferas individual e social teriam sido separadas artificialmente pelos pensadores, gerando um paradoxo de resolução impossível, no entanto, na realidade, elas são inseparáveis. Todavia, tal postura epistemológica leva à valorização da biografia enquanto método sociológico, na medida em que torna indispensável conhecer os indivíduos para conhecer a sociedade.

Entretanto, a dimensão temporal em seu sentido histórico-social permanence sob controle, tanto em Elias (1994) quanto em Bernard Lahire (2004). Este último, por exemplo, dá importância ao contexto histórico do capitalismo avançado pós-globalização, para afirmar que os indivíduos entrevistados para o livro Retratos Sociológicos têm processos de socialização mais flexíveis que os que viveram nos anos 1950. Contudo, essa importância é limitada, já que o dado histórico não é desenvolvido empiricamente, nem no contexto de uma reflexão concernente ao devir dos sistemas de produção de bens, conforme as teorias históricas ou o marxismo. O foco permanece nos processos de socialização em si.

Nas teorias disposicionalistas há uma ruptura com relação ao devir histórico, no sentido dado por Wright Mills (1975) em A Imaginação Sociológica. Para ele, a existência da sociedade é mais longa que a do indivíduo, sendo que a segunda está contida na primeira. Portanto, a biografia 
individual está situada no devir histórico social e ambos são mutuamente condicionados. Em termos práticos, é impossível conhecermos a vida de um indivíduo sem localizá-la num período específico da história da sociedade em que ele vive. É também impossível conhecermos uma sociedade sem saber algo sobre as vivências e experiências dos indivíduos que nela interagem. Muito embora biografia e história tenham relações incontornáveis de interdependência, estas não são completas, nem totalizantes. Há dimensões de descoincidência entre uma e outra. Descobrir, no estudo das trajetórias de vida dos indivíduos, o interstício desta descoincidência, que se caracteriza pela rapidez com que muda sua manifestação, nas sociedades contemporâneas, é a possibilidade empírica oferecida pelo método biográfico aos disposicionalistas de qualquer matiz.

\section{O artigo A Ilusão Biográfica}

O uso da abordagem biográfica sempre mobilizou cuidados na área das Ciências Sociais. De um lado, devido à desconfiança de que o seu emprego trouxesse de volta o mito do eu, do individualismo subjetivo, num movimento de psicologização indesejável ao tratamento do objeto destas ciências. De outro lado, sempre se questionou a validade da narrativa pessoal na condição de dado científico. Existe o pressuposto de que o entrevistado ou o autobiografado produzam discurso distorcido pelo ego, de forma a qualificar a própria personalidade e percurso, além da realidade, na direção da idealização de si mesmo. Pierre Bourdieu veio explicitar estes problemas de racionalização retrospectiva da vivência social e da apresentação pessoal do indivíduo, no âmbito da perspectiva disposicionalista. Publicou um artigo, na forma de introdução ao número da Revista Actes de la Recherche en Sciences Sociales de 1986, sob o título A Ilusão Biográfica, que se tornou um marco para os estudos da abordagem biográfica nas Ciências Sociais, principalmente na Sociologia.

Os questionamentos à abordagem biográfica apresentados no artigo podem ser resumidos em três pontos interrelacionados: o problema da definição de história, a ilusão de transparência do real e a produção de discurso na entrevista.

O problema da definição de história diz respeito à ideia disposicionalista segundo a qual a história de indivíduos e sociedade seria uma só, mas que se manifesta em diferentes estados. No artigo Le mort saisit le vif, Bourdieu (1980) já alertava para a diferença entre a história no estado objetivado, que é a forma como ela se apresenta pelas instituições normativas, e a história no estado incorporado, aquela produzida no cotidiano através do senso prático. A socialização progressiva, desde a primeira infância, até a idade adulta, é a "fonte das disposições adquiridas sob a forma de estruturas mentais e de esquemas de percepção e de julgamento, e mesmo de modos corporais (hexis) adquiridos no curso da existência.” (GRINGRAS, 2000, p.126). Portanto, o indivíduo não vive somente seu presente, mas também o passado no estado incorporado, transformado em habitus. No artigo A Ilusão Biográfica, Bourdieu aprofunda esta ideia de que o eu não é substancial, mas relacional. 
Sem sair dos princípios da sociologia, como responder à velha questão empírica a respeito da existência de um eu irredutível à rapsódia de sensações singulares? Sem dúvida, podemos encontrar no habitus o princípio ativo, irredutível às percepções passivas, de unificação das práticas e das representações (isto é, o equivalente, historicamente constituído, logo, historicamente situado, desse eu cuja existência devemos postular, de acordo com Kant, para dar conta da síntese da diversidade sensível intuída e da coerência de representações em uma consciência). Mas essa identidade prática só se entrega à intuição na inesgotável e inapreensível série de suas manifestações sucessivas, de modo que a única maneira de apreendê-la como tal, consiste em talvez apanhá-la na unidade de uma narrativa totalizante (como autorizam as várias maneiras, mais ou menos institucionalizadas, de "falar de si", da confidência etc.) (BOURDIEU, 1996, p. 77).

O problema da ilusão da transparência do real diz respeito à relação entre objetividade e subjetividade. Passeron, em concordância com Bourdieu, foi o primeiro a deixar claro o raciocínio epistemológico do disposicionalismo, que consiste em retirar a objetivação da subjetividade e a subjetivação da objetividade (PASSERON, 1990). Neste procedimento mental, a abordagem biográfica deve ser o tempo todo colocada em questão por todas as formas pelas quais ela sofre influências da objetividade da vida, da concretude que provém da sua condição de existir no interior de uma rede de relações.

As leis que regem a produção de discursos na relação entre um habitus e um mercado aplicam-se a essa forma particular de expressão que é o discurso sobre si; e a narrativa de vida vai variar, tanto em sua forma quanto em seu conteúdo, conforme a qualidade social do mercado no qual será apresentada - a própria situação da pesquisa contribuindo, inevitavelmente, para determinar a forma e o conteúdo do discurso recolhido (BOURDIEU, 1996, p. 80).

O mercado social implica todo o contexto acadêmico, com seu complexo ritualístico característico do campo intelectual, no caso da pesquisa sociológica biográfica, mas também os campos sociais de pertencimento do entrevistado, acrescentando-se a ambos os palcos da apresentação das informações coletadas.

O terceiro problema, já anunciado no segundo e comentado acima, é o da produção do discurso da narrativa de vida no âmbito da entrevista biográfica. Segundo Durand (2008), tomar uma vida narrada como fato social, ao mesmo tempo encarnada por um indivíduo e considerada enquanto experiência coletiva do mundo pressupõe admitir disparidades, incoerências, enigmas, resistências à elucidação sociológica. A biografia construída no ato da pesquisa, pede que uma gênese ou genealogia das disposições do indivíduo seja colocada em correlação com um conjunto de posições sociais tomadas ao longo da vida, sem negligenciar que as posições no campo não definem mecanicamente a biografia. As forças de produção de si, combatem sempre, em algum grau, as forças da reprodução (DURAND, 2008). 
A dimensão narrativa da abordagem biográfica deve ser pensada em relação à dimensão dialógica instalada no contexto da sua produção na entrevista, propondo considerar a intersubjetividade da situação. Esta, por sua vez, é também social, na medida em que toda interação social participa dos ritos institucionalizados, a começar pela distribuição de papéis sociais, poderes, recursos, capital social, que são organizados por normas, valores e regras predefinidas.

A análise crítica dos processos sociais mal-analisados e mal-compreendidos que estão em jogo, sem que o pesquisador o saiba, na construção dessa espécie de artefato irrepreensível que é a "história de vida", não é a sua finalidade. Ela leva à construção da noção de trajetória como uma série de posições sucessivamente ocupadas por um mesmo agente (ou um mesmo grupo), em um espaço ele próprio em devir e submetido a transformações incessantes (BOURDIEU, 1996, p. 81).

Para o autor, a distância entre entrevistador e entrevistado e a representação que este faz da situação de entrevista são fatores essenciais a serem considerados para entender a produção discursiva que o entrevistado faz de si mesmo, em outras palavras, para entender os dados de pesquisa coletados.

Bourdieu não elimina a possibilidade de utilização da biografia na pesquisa disposicionalista, considerando-a método menor ou menos adaptável à sua teoria. Apenas condiciona sua utilização ao desenvolvimento, pelo pesquisador, da sensibilidade necessária à abordagem relacional, à perceptibilidade do funcionamento das redes sociais, situando a narrativa do entrevistado no contexto dos campos e sua circulação de capitais e poder, e dos habitus e o correspondente desenvolvimento de disposições sociais, em coerência com a construção lógica que é própria da perspectiva disposicionalista. Para ele:

\footnotetext{
Os acontecimentos biográficos definem-se antes como alocações e como deslocamentos no espaço social, isto é, mais precisamente, nos diferentes estados sucessivos da distribuição dos diferentes tipos de capital que estão em jogo no campo considerado (...) Não podemos compreender uma trajetória (...) a menos que tenhamos previamente construído os estados sucessivos do campo no qual ela se desenrolou. (...) Essa construção prévia é também condição de qualquer avaliação rigorosa do que poderíamos chamar de superfície social, como descrição rigorosa da personalidade designada pelo nome próprio, isto é, o conjunto de posições simultaneamente ocupadas, em um momento dado do tempo, por uma individualidade biológica socialmente instituída, que age como suporte de um conjunto de atributos e de atribuições que permitem sua intervenção como agente eficiente nos diferentes campos (BOURDIEU, 1996, p. 82).
}

Esta posição muito crítica de Bourdieu com relação ao método biográfico nos seus escritos dos anos 1970 e 1980, parece ter se suavizado nos anos 1990. De fato, o autor utilizou a biografia e a autobiografia em algumas ocasiões, levantando questionamentos a respeito de sua posição sobre o assunto, conforme havia sido colocada no artigo A Ilusão Biográfica. É digna de nota a publicação do livro A Miséria do Mundo em que Bourdieu (1998) utiliza relatos biográficos quase 
completamente desacompanhados de estudos e análise sociológica, ainda menos de reflexões a respeito da abordagem biográfica utlizada. Também é importante citar o esforço realizado pelo autor para situar sua vida e obra no tempo social em que viveu, através do livro Esquisse pour une auto-analyse, escrito em 2001, pouco antes de sua morte em 2002. Trata-se de um relato pessoal repleto de lembranças do passado, onde o autor sublinhou fortemente as dificuldades enfrentadas na vida para se situar nos campos sociais em que atuou, mostrando forte rebelião ao ambiente acadêmico e científico, onde fez sua profissão e seu renome, e desejando deixar de si mesmo o exemplo para que os leitores, agentes no mesmo campo ou não, pudessem se identificar e viver um pouco melhor as mesmas ou similares dificuldades (BOURDIEU, 2004).

Uma terceira evidência da relativização da resistência de Bourdieu à abordagem biográfica no fim da vida é o filme de Pierre Carles La sociologie est un sport de combat (A sociologia é um esporte de combate), documentário em que o autor mais uma vez retoma sua trajetória publicamente, fazendo justificativas científicas e se colocando como exemplo para os sociólogos mais jovens. O filme é tocante se levamos em conta que o protagonista que temos diante de nós foi um grande empresário científico, cuja enorme empresa desenvolveu inúmeras ramificações nacionais e internacionais (SAINT MARTIN, 2004), dizendo que se fez sozinho, que lutou contra tudo e contra todos e desejando que seu depoimento possa ajudar outros a tentar a mesma vitória, a enfrentar os mesmos desafios.

Bernard Lahire, no contexto da diatribe de Bordieu e sua obra sobre a qual construiu seu próprio posicionamento intelectual, critica, no livro Esquisse pour une auto-analyse, a ausência de análise de outros tipos sociais próximos que Bourdieu poderia ter relacionado para uma exposição mais científica. Afirma que nele se constata a ausência da perspectiva contextualizadora, do fornecimento mínimo de pistas das disposições sociais pessoais do autor desenvolvidas e das relações estabelecidas que fornecessem o panorama relacional explicativo da trajetória pessoal. Contraditoriamente, elementos metodológicos tão cobrados pelo autor no texto A Ilusão Biográfica estariam sendo negligenciados. Na sua autoexposição, segundo Lahire, Bourdieu teria se limitado diante de tantas ausências, as quais, finalmente, o levaram ao uso subjetivista da biografia que ele mesmo tanto criticava (LAHIRE, 2004).

Críticas como a de Lahire não diminuíram a importância do artigo A Ilusão Biográfica enquanto referência para estudos envolvendo a referida abordagem. $O$ interesse pela explicação da complexidade do método feita no artigo levou o disposicionalismo a ser debatido em outras ciências como por exemplo a História (GINGRAS, 2000), Psicologia (GAUTHIER, 2014; GAULEJAC, 2012), Educação (MOELO, 2003; COSTA, 2010), Administração (FILLION, 2012), Ciências Médicas (MONTAGNER, 2007), entre tantas outras. O próprio Lahire fez dele artigo de referência tanto positiva quanto negativa. Procurou observar os apontamentos nele contidos no seu empreendimento sociológico-disposicionalista pessoal, não obstante o tenha desenvolvido bem além, sublinhando suas limitações para uma aplicabilidade contemporânea e fazendo outras críticas. 


\title{
Lahire e a superação da Ilusão Biográfica
}

Lahire situa a biografia no coração da mais importante meta da Sociologia, que é a de explicar porque os indivíduos fazem o que fazem (ação social), dizem o que dizem (interação social) e pensam o que pensam (representações sociais). Nesse caso, o pesquisador precisa superar as investigações convencionais de trajetórias individuais, as quais se contentam em colecionar propriedades e características, tais como origem social, diploma, profissão, mas ir além e reconstuir a linha das experiências específicas através das quais essas propriedades foram adquiridas. A biografia serve à pesquisa disposicionalista, na perspectiva de Lahire, para problematizar o curso da vida do indivíduo, do ponto de vista sociológico e não para explicar somente sua posição social em espaços determinados de um campo.

\begin{abstract}
Se procuramos trazer à tona as estruturas mentais e comportamentais de um indivíduo, suas inclinações as mais singulares assim como as gerais, os problemas mais importantes que estas condições de existência e de coexistência, passadas e presentes, $o$ conduziram a se colocar e a enfrentar, só a biografia sociológica pode permitir levantar precisamente os quadros sociais que ele frequentou e os traços que eles deixaram mais ou menos duravelmente nele. Não existe, portanto, nenhuma ilusão em proceder à análise biográfica se damos a esta o papel de levantar a natureza das experiências sedimentadas em um indivíduo determinado. Em revanche, pode-se reprovar à teoria dos campos de passar totalmente ao largo das diferentes etapas e das diferentes dimensões da socialização dos atores, tornando, a partir daí, invisível tudo o que eles investem em sua escrita (LAHIRE, 2010, p. 39).
\end{abstract}

À medida que o indivíduo percorre seu caminho pessoal de experiências determinadas, ele atravessa quadros socializadores diferenciados, que deixam marcas em sua maneira de pensar, expressar-se e agir. Tanto o caminho quanto as experiências individuais são personalíssimas. Por isso, Lahire não prioriza a busca de similaridades entre conjuntos de trajetórias, procurando reuni-las, através da genética social do habitus, em um espaço comum junto a outras. Ao contrário do que Bourdieu (1980) fazia com a teoria do pertencimento aos campos sociais, ele não pretende mostrar a homogeneidade das trajetórias de determinados grupos.

Interessa mais a ele estudar o grau de importância que cada experiência teve na socialização do indivíduo. Por exemplo, experiências mais marcantes, que se repetiram várias vezes, podem ter deixado marcas mais fortes. Dentro de um leque de variação amplo que vai das influências mais leves às mais fortes, estas últimas apresentam potencial para a investigação, ao mostrar se têm interferência nas disposições sociais do indivíduo que as vivenciou, ou não. Pela abordagem microssociológica proposta por Lahire não é necessário buscar o social nos campos, na sua dimensão institucionalizada, já que ele se encontra na experiência vivida e incorporada pelos indivíduos.

Cabe também ao pesquisador analisar, em cada experiência vivida, as marcas de experiências passadas, bem como o campo de possibilidades aberto para experiências futuras. 
Nesse sentido, é dada importância singular à dimensão diacrônica na análise. Por essa razão, também, não interessa a Lahire (2004) estudar todos os acontecimentos da vida de um indivíduo, o que seria impossível e irrealista, mas selecionar criteriosamente os eventos, levando em consideração sua potencialidade para gerar, reforçar ou criar novas disposições sociais.

O autor leva em conta, também a dimensão sincrônica do processo, considerando a multiplicidade de mundos sociais simultâneos, vivenciados pelo indivíduo. Desse modo, importam as variadas cenas sociais atravessadas, as múltiplas interações realizadas, todas acarretando a própria panóplia de papéis sociais a representar, de normas e rituais a respeitar. "O ator tem tanto mais chance de ser plural de um ponto de vista disposicional quanto mais ele viva em uma sociedade altamente diferenciada e que ele frequente mais ou menos precocemente uma pluralidadade de contextos socializadores heterogêneos." (LAHIRE, 1998, p. 115).

Uma das críticas mais sérias feita por Lahire aos estudos de Bourdieu é que não se pode reduzir a experiência individual à sua atuação em um campo social, na sociedade contemporânea. Experiências vividas por indivíduos em diferentes universos não são necessariamente convergentes e coerentes entre elas. Os efeitos podem ser muito diferentes. A mesma experiência vivida por um indivíduo pode ter sido marcante e movimentado sua bagagem de disposições, quando, para outra pessoa, não teve nenhuma importância no curso da sua trajetória. O autor expõe esta complexidade na introdução do livro $A$ Condição Literária, para explicar a abordagem biográfica disposicionalista realizada na pesquisa sobre os escritores, evidenciando as inter-relações entre trajetórias individuais e a rede social na qual atuam. Na citação a seguir, quando se refere à condição de dupla vida do escritor, Lahire quer evidenciar que, para a maioria dos escritores estudados, a escrita de livros não é sua ocupação professional principal. A maioria tem um emprego que lhe proporciona a renda necessária para a sobrevivência e utiliza o tempo livre na agenda pessoal para exercer a atividade da escrita.

O procedimento sociológico que eu adoto coloca no coração da interrogacão a variação intraindividual das inscrições sociais (o fato de que os atores tenham que gerir em permanência a passagem de um universo social a outro) e tenciona descrever e interpretar as condições de dupla vida assim como os problemas concretos que encontram os escritores submetidos a essas pressões em seu trabalho (sua organização, sua realização ou suas descontinuidades). Ela pode também dar visibilidade à proximidade de situações vividas pelos escritores - problemas aos quais eles são confrontados e as soluções que eles dispõem - cujas posições no jogo literário são portanto às vezes muito diferentes, ou até mesmo opostas: escritores cuja produção literária se situa no setor comercial ou no setor mais "literário", escritores muito reconhecidos, em vias de reconhecimento ou ainda desconhecidos. $\mathrm{O}$ aporte desta pesquisa ao conhecimento do mundo social se situa, portanto, tanto do lado da exploração dos patrimônios individuais das disposições próprias às situações de dupla vida quanto do lado da análise de esferas de atividade diferenciadas, cuja "teoria dos campos" só constitui uma formulação parcial e insuficientemente especificada. O aporte é duplo, mas perfeitamente 
congruente, na medida em que ele importa à teoria das esferas de atividades diferenciadas (ou da diferenciação social das esferas de atividades) de levar em conta que não são sempre indivíduos diferentes que ocupam posições diferentes na divisão social do trabalho (LAHIRE, 2006, p. 29). ${ }^{2}$

Daí resulta que a investigação tem que respeitar a singularidade de cada caso. Esta é a síntese empírica do que Lahire chama de estado social dobrado. O social se encontra na própria razão do fato do indivíduo passar por experiências determinadas (em parte devido ao pertencimento às condições sociais de origem), mas também nas minuciosas formas como ele atravessa cada uma delas, e nos modos personalíssimos pelos quais tê-las vivido interfere na sua socialização e na sua atitude nas situações no presente. A abordagem biográfica permite ao pesquisador chegar a este devir do indivíduo, o qual é carregado de conteúdo social, em cada ponto da sua existência na sociedade.

De alguma maneira, cada indivíduo é o "depositário" de disposições de pensamento, sentimento e ação, que são produtos de suas experiências socializadoras múltiplas, mais ou menos duradouras e intensas, em diversos grupos (dos menores aos maiores) e em diferentes formas de relações sociais. Se não me equivoco quando afirmo que o social, incorporado como objetividade, nunca existe em estado desdobrado para os atores individuais, então devemos nos perguntar quais são as imagens científicas do mundo social que podem respeitar essas propriedades e quais as destroem sistematicamente. Nessa versão dobrada da realidade que pretendo elaborar, o indivíduo não é redutível a seu protestantismo, ao seu pertencimento de classe, a seu nível cultural ou ao seu sexo. É definido pelo conjunto de suas relações, compromissos, pertencimentos e propriedades, passados e presentes. Neles sintetizam-se ou se combatem, combinam-se ou se contradizem, articulam-se harmonicamente ou coexistem de forma mais ou menos pacífica, elementos e dimensões de sua cultura (no sentido amplo do termo) que, em geral, são estudados separadamente pelos pequisadores na área das ciências sociais (LAHIRE, 2004, p.10).

Partindo dos elementos aqui elencados, é possível afirmar que a proposta apresentada por Lahire para utilização da abordagem biográfica na pesquisa disposicionalista atende as exigências básicas demandadas por Bourdieu. Lahire, assim como Bourdieu, defende os três elementos básicos da pesquisa biográfica estipulados no artigo A Ilusão Biográfica. Para ele, o conceito de história está interligado à histórica individual, considerando o social em estado incorporado. Lahire desenvolve este item aprofundando a ideia de estado dobrado. Defende a superação da ilusão de transparência do real proposta por Bourdieu, na medida em que preserva a ideia de considerar o discurso do entrevistado não enquanto expressão de uma individualidade meramente subjetiva, mas retirar dela a objetividade da sociedade na qual o indivíduo transita; entendendo, ao mesmo tempo, tal objetividade em seu estado interiorizado na ação social, presente na forma de agir e de pensar individuais. Finalmente, Lahire também se preocupa com 
a produção de discurso na entrevista, sugerindo os cuidados de distanciamento necessários para que o instrumento e os dados obtenham fiabilidade mais significativa.

Partindo da preservação dos princípios fundamentais da abordagem biográfica apontados no artigo A Ilusão biográfica, Lahire vai mais além e atualiza o método para atender à complexidade dos fenômenos sociais de hoje. Nesse sentido, a abordagem biográfica não mais se limita a consideração da trajetória individual do agente para que seja adaptável a um campo social de manifestação, preponderante na idade adulta. A análise biográfica percorre, no seu modo particular de apropriação, a diversidade das instâncias de manifestação individual, hora focando em elementos mais subjetivos, hora em outros mais objetivos. Ela se flexibiliza para ajustar-se melhor ao ritmo mais veloz e à diversidade crescente da manifestação individual na multitude dos mundos sociais, na pluralidade de papéis sociais e na variedade de disposições sociais que o indivíduo pode apresentar ao transitar pela vida. Trata-se de adaptar a metodologia ao "nível de realidade social visado, às escalas de observação adotadas, e aos problemas que se quer levantar a seu respeito" (LAHIRE, 2012, p. 57). Ao mesmo tempo, tal flexibilidade da abordagem biográfica permite evidenciar as idiossincrasias de grupos e ambientes sociais específicos, nos quais certas trajetórias individuais podem se desenvolver mais adstritamente. A abordagem de Lahire, portanto, acrescenta positividade e dá maior valor explicativo, a este instrumento de pesquisa que se torna ainda mais interessante de ser utilizado nas pesquisas sociais sob a ótica do disposicionalismo.

A proposta colocada para este artigo, a qual propôs problematizar o uso das abordagens biográficas na Sociologia Disposicionalista, apontando os avanços alcançados por Lahire neste item, chega ao seu resultado. A utilização apresentada por Bernard Lahire dos métodos biográficos se apresenta inovadora, criativa e atual, na medida em que o autor opera uma ressignificação positiva, utilizando a investigação de trajetórias de vida de maneira original, ao propor a superação da ideia da ilusão biográfica, entre outras inovações.

\section{Referências}

BERTAUX, Daniel. Le récit de vie. 2 ed. Paris: Colin, 2006.

BOURDIEU, Pierre. Le mort saisit le vif. Actes de la Recherche en Sciences Sociales, Paris, v. 32-33, p. 3-14, abr./ jun., 1980.

BOURDIEU, Pierre. A ilusão biográfica. In: Razões Práticas. Sobre a teoria da ação. São Paulo: Papirus, 1996. p. 74-82.

BOURDIEU, Pierre. Esquisse pour une auto-analyse. Paris: Seuil, 2004.

BOURDIEU, Pierre. La Misère du Monde. Paris: Seuil, 1998.

BUTNARU, Denise; KELLER, Reiner. Temps et écrit. Les défis de l’approche biographique dans la sociologie française des années 80. In: CONGRÈS DE L’ASSOCIATION FRANÇAISE DE SOCIOLOGIE, 5, 2013, Nantes. Analles du Congrès de l'Association Française de Sociologie. Nantes: Université de Nantes, 2013. p. 234-261. 
COSTA, Luciano Bedin. Biografema como estratégia biográfica: escrever uma vida com Nietzche, Deleuze, Barthes e Henry Miller. 2010. Tese (Doutorado em Educação) - Programa de Pós-graduação em Educação, Universidade Federal do Rio Grande do Sul, Porto Alegre, 2010.

DURAND, Pascal. Ilusion biographique et biographie construite. Contextes, Bruxelas, v.2, n.3, p. 2-9, jun. 2008. Disponível em: http://contextes.revues.org/index1983.html Acesso em: 21 out. 2018.

ELIAS, Norbert. O Processo Civilizador. Uma história dos costumes. v. 1. Rio de Janeiro: Zahar, 1994.

FILION, Loui Jacques; AKIZAWA, Hikari. La méthode biographique. Approche structurante pour l'étude des représentations entrepreneuriales. La cognition entrepreneuriale. Revue internationale de psychosociologie et de comportement organisationnel, Liège/Paris, v. 18, n. 44, p. 117-146, 2012.

GAULEJAC, Vincent. L'Histoire en héritage. Roman familial et trajectoire sociale. Paris: Desclée de Brouwer, 1999. Nouvelle édition (poche): Petite Bibliothèque Payot, 2012.

GAUTHIER, Pascale. Théorie du parcours de vie. Cahier de Recherche du Centre d'Études et de Recherche en Intervention Familiale, Québec, v.6, n. 6, p. 2-22, nov. 2014.

GINGRAS, Yves. Pour une biographie sociologique. Revue d'Histoire de l'Amérique Française, Québec, v. 54, n. 1, p. 123-131, 2000. Disponível em: https://archipel.uqam.ca/446/1/RHAF_2000.pdf. Acesso em 21 out. 2018.

HOULE, Gilles. La Sociologie comme science du vivant: l'approche biographique. In: TREMBLAY, Jean-Marie (org.). La recherche qualitative. Enjeux épistémologiques et méthodologiques. Montréal: Gaëtan Morin Éditeur, 1997. p. 5-31.

La Sociologie est um sport de combat. Direção: Pierre Charles. 146 min. Disponível em:https://archive.org/details/Pierre.CarlesLa.sociologie.est.un.sport.de.combat.avec.Pierre.Bourdieu. Acesso em: 20 nov. 2018.

LAHIRE, Bernard. Analyse sociologique de soi et cousinages intellectuels. Autobiographe ou auto-analyste? Revue Mouvements, Paris, n. 35, p. 32-45, set./out. 2004.

LAHIRE, Bernard. La Condition littéraire. La double vie des écrivains. Paris: La Découverte, 2006.

LAHIRE, Bernard. L'homme pluriel. Les resorts de l'action. Paris: Nathan, 1998.

LAHIRE, Bernard. Franz Kafka. Élements pour une théorie de la création littéraire. Paris: La Découverte, 2010.

LAHIRE, Bernard. Monde pluriel, penser l'unité des sciences sociales. Paris: Seuil, 2012

LAHIRE, Bernard. Retratos Sociológicos. Disposições e variações individuais. Porto Alegre: Artmed, 2004.

LE GRAND, Jean Louis. Étude d'une experience communautaire à orientation thérapeutique. Histoire de vie de groupe. Perspectives Sociologiques. 1987. Tese (Doutorado em Sociologia) - Université Paris VIII, Paris, 1987.

LE JEUNE, P. L’autobiographie en France. Paris: Armand Colin, 1971.

MILLS, Wright. A Imaginação Sociológica. Rio de janeiro: Civilização Brasileira, 1975.

MOELO, Hervé. Lécriture sous contrôle: biographie et formation de soi. Revue Les Actes de la Lecture, Paris, $n$ 84, p. 84-92, dez. 2003.

MONTAGNER, Miguel Ângelo. Trajetórias e biografias: notas para uma análise bourdieusiana. Sociologias, Porto Alegre, n. 17, p. 240-264, jan./jun. 2007.

PASSERON, Jean-Claude. Biographies, flux, itinéraires, trajectoires. Revue Française de Sociologie, Paris, v. 31, n. 1, p. 3-22, 1990.

PINEAU, Gaston., LE GRAND, Jean-Louis. Histoires de vie. Que sais je? Paris: PUF, 2007.

SAINT MARTIN, Monique de. Un livre testament. À mi-chemin entre l'auto-analyse et l'auto-réprésentation. Revue Mouvements, Paris, n. 35, p.12-35, set./out. 2004.

Recebido em: 16/12/2018 